\title{
1. Entrepreneurship education ecosystems: the case of Babson College
}

\author{
Candida G. Brush (Babson College, USA)
}

\section{INTRODUCTION}

Entrepreneurship education in colleges and universities has risen dramatically over the past few decades. In the year 2000, there were 2000 colleges and universities in the United States offering courses in entrepreneurship. More recent numbers show that around the world, there are more than 5000 courses offered, and more than 250 schools offer entrepreneurship majors (Finkle et al., 2013). ${ }^{1}$ In addition, more than 240 universities have centers, institutes, and co-curricular programs. ${ }^{2}$ This rise in courses and programs coincides with the significant growth in research in entrepreneurship as a field of study (Busenitz et al., 2003; Davidsson, 2016). The field boasts more than 150 refereed journals providing publication outlets for all types of research; and the Entrepreneurship Division of the Academy of Management, which is the third largest division in this organization, now has 3900 members worldwide.

Concurrent with the expansion of the field of entrepreneurship, colleges and universities are seeking new ways to serve students, create distinctive and unique programming, integrate curricular and co-curricular activities, and amplify the brand and reputation of their schools. This chapter presents an entrepreneurship ecosystem framework, arguing that unique opportunities for innovation in entrepreneurship education lie at the intersections of curricular and co-curricular research and outreach. The following sections define the entrepreneurship education ecosystem framework, then, using Babson College as a case study, explore the intersections across domains and identify examples of innovations. Conclusions and implications are offered.

\section{ENTREPRENEURSHIP EDUCATION ECOSYSTEM FRAMEWORK}

Developing entrepreneurship ecosystems has emerged as a popular topic around the world. It is perceived as a solution to both social and economic problems (Isenberg, 2010; Bosma and Kelley, 2019). Entrepreneurship ecosystems include a conducive culture, the availability

\footnotetext{
See https:/www.kauffman.org/currents/2015/10/the-evolution-of-entrepreneurship-on-coll ege-campuses.

See https://sites.google.com/a/slu.edu/eweb/list-of-colleges-with-majors-in-entrepreneurship -or-small-business, https://www.acceleratorinfo.com/see-all.html.
} 
of financing, the acquisition and development of human capital, new markets for products and services, and a range of institutional and infrastructural supports (Isenberg, 2010; WEF, 2013). These elements are dynamic, and the actors and institutions are interdependent, as they influence and are influenced by their unique entrepreneurship ecosystem (Feld, 2012; Spigel, 2017).

A significant aspect of entrepreneurship ecosystems is the role of academic institutions in educating entrepreneurs, developing technology, and connecting entrepreneurs to resources and interactions that support economic development and innovation. ${ }^{3}$ Universities are a hub of economic development around the world, providing infrastructure, resources, training, and a means to develop entrepreneurial communities (Fetters et al., 2010). These authors argue that entrepreneurship education ecosystems include multi-dimensional enterprises that support entrepreneurial development through a variety of activities related to teaching, outreach and research (Fetters et al., 2010). Brush (2014) expanded this definition to characterize university entrepreneurship education ecosystems to include a set of dimensions and domains (Figure 1.1).

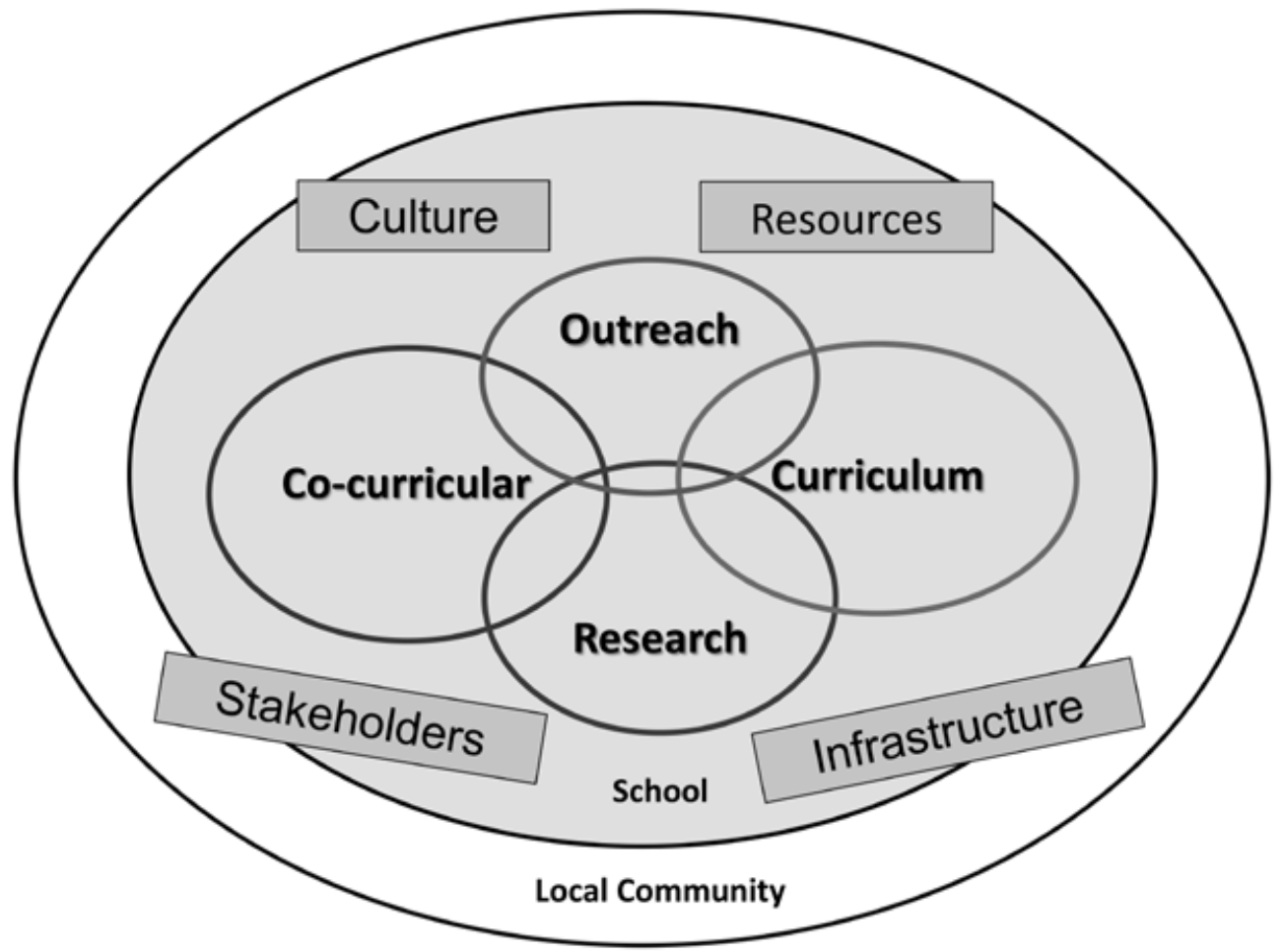

Figure 1.1 Dimensions and domain of entrepreneurship

3 See http://www.technologyreview.com/article/14761/; http://www.xconomy.com/boston/20 08/02/25/universities-an-entrepreneurs-ecosystem/. 
Dimension aspects of university entrepreneurship education ecosystems consist of stakeholders, infrastructure, resources and culture (Brush, 2014). Stakeholders are all those involved in the three core aspects of entrepreneurship education: curriculum, co-curricular activities, and research (e.g., faculty, staff, leadership and administration, students, parents, alumni, service providers, service and infrastructure staff, marketing and PR, and partners). Infrastructure, generally considered to be the physical campus (roads, buildings, facilities), also includes the technological or digital environment (internet, communications, computer platforms, telephone system). This is the technology platform within which people communicate and interact. Infrastructure also includes the distribution channels for information, marketing, branding, and positioning the school. Resources include money, technology, physical facilities, social capital, organizational partnerships, and the capabilities and skills of faculty and staff. Resources can be generic or commodities similar to those at other schools, or they may be unique and hard to replicate. Culture includes the symbolic aspects, norms, values and traditions of the school. Culture is the touch and feel of the campus, the intangibles and core values that guide work in the school. This is related to the school mission and definition of entrepreneurship. Culture is infused within the domain (curriculum, co-curricular and research). It influences behavior and communications.

Domain aspects of entrepreneurship education ecosystems comprise curriculum, co-curricular activities, research and outreach (Brush, 2014). Entrepreneurship curriculum is a set of courses organized by discipline, program, or concentration for a degree. Co-curricular activities are all non-degree-bearing (ungraded) activities that enrich the student learning experience. These include (but are not limited to) programs, clubs, accelerators, incubators, living experiences, workshops, guest speakers, forums, business plan competitions, networking, and other programs. Research covers both theoretical and applied research across a broad domain and includes theoretical and applied research. Theoretical research has a goal of proving or disproving a hypothesized truth, while applied research investigates applied and practical questions about a topic or phenomenon. Building on this framework, outreach as a key domain area was added as this is an important consideration for how schools raise funding and connect with alumni (Finkle et al., 2013). Outreach includes programming, workshops, executive education programs, alumni activities, mentoring programs, and other events provided for non-college/university students to engage members of the community at large.

Entrepreneurship education ecosystems include all these elements, although schools have different priorities and strategies and are likely to emphasize different domain and dimension combinations. Some schools may choose to focus more on selected aspects, for instance curriculum (e.g., courses and majors), while others may focus on co-curricular (events, business plan activities) or outreach (training entrepreneurs in the community) (Brush, 2014). The focus on these domain items is also influenced by the dimensions, for instance, the extent to which entrepreneurship is embedded in the culture, the resources dedicated to supporting entrepreneurship, and the strength of stakeholder groups advancing entrepreneurial activities. In the case of Babson College, the commitment to entrepreneurship is longstanding and comprehensive across the institution, driven by the mission and supported by stakeholders and resources. Babson represents a good case study for understanding how dimensions and domain interact to build one of the world's most robust entrepreneurship education ecosystems. 


\section{THE ENTREPRENEURSHIP EDUCATION ECOSYSTEM AT BABSON COLLEGE}

In 1978, Babson College committed to entrepreneurship education as a strategic position under President Ralph Sorenson. ${ }^{4}$ From that point in time, the mission of the College has been "to create entrepreneurial leaders of all kinds who create social and economic value." With this mission as a guide, the College created the first Center for Entrepreneurial Studies, first undergraduate major in entrepreneurship, first award ceremony celebrating distinguished entrepreneurs (The Academy of Distinguished Entrepreneurs), first business plan competition, and first full-time MBA program with entrepreneurship at its core. Babson launched the first global academic research conference, the Babson College Entrepreneurship Research Conference (BCERC). ${ }^{5}$ The BCERC to this day remains the premier research conference in entrepreneurship, with more than 350 scholars attending every year, and a total of more than 5000 having presented papers over the history of the event. Babson also started the first teacher training program for entrepreneurship educators (the Price-Babson Symposium for Entrepreneurship Educators). Since 1986, the Symposium has trained close to 6000 educators from 85 countries.

Over the next 50 years, Babson College continued to invest and amplify its commitment to entrepreneurship in all four areas of its entrepreneurship education ecosystem: research, curricular, co-curricular and outreach. Today, Babson is defined by a broader and more inclusive approach to entrepreneurship education. Using its own methodology grounded in effectuation theory (Sarasvathy, 2008), Entrepreneurial Thought \& Action ${ }^{\circledR}$ (ET\&A) encourages learners to take smart action under conditions of uncertainty and ambiguity. It is based on four operating premises: start with the means at hand, pay only what you can afford to lose, take small action, enroll others and build on what you learn. The ET\&A approach helps nascent and novice entrepreneurs assess feasibility and drivers of opportunities, develop viable business models, and take swift, smart action with the goals of starting small but thinking big.

On the curricular side, Babson College has a separate department of entrepreneurship faculty, today numbering 45 people, all with entrepreneurial experience of some kind. Unlike with most schools, entrepreneurship is a required course for every student. More than 20 entrepreneurship electives are available to undergraduate students, and graduate students have a choice of more than 30 unique electives. A notable innovation is the award-winning undergraduate first course, Foundations of Management and Entrepreneurship (FME). All students participate in this course, which includes an ideation and design thinking phase to develop an idea or initiative, followed by formation into companies, which develop, launch and manage a venture with real products and services. ${ }^{6}$ The course is run by two dedicated

$4 \quad$ An independent, not-for-profit institution, Babson is accredited by the Association to Advance Collegiate Schools of Business (AACSB), the New England Association of Schools and Colleges, and the EFMD Quality Improvement System (EQUIS). In the academic year 2018-19, more than 2350 undergraduate students and nearly 1000 graduate students attended Babson, representing more than 80 countries.

5 See https:/www.babson.edu/academics/centers-and-institutes/the-arthur-m-blank-center-for -entrepreneurship/about/history/.

6 See https:/www.babson.edu/academics/undergraduate-school/core-experiences/foundations -of-management-and-entrepreneurship/. 
faculty members, one with specialization in entrepreneurship and the other with specialization in organizational behavior. Further, the College loans student teams up to $\$ 3000$ as start-up funding. The course content includes entrepreneurship, marketing, accounting, organizational behavior, information systems, and operations. Students launch their business and sell the product and/or service for four months. Key areas of emphasis are communication, leading and working in a team, and seeing a business action plan through to completion. Late in the second semester of the course, students will harvest their business, pay back their loan to the College, and give a presentation about what they learned in the class. Each team partners with a local non-profit where they volunteer, and the students donate at least 50 percent of their profits to the organization after paying back the loan to Babson (Greenberg and Hunt, 2015).

Importantly, the definition of entrepreneurship at Babson College focuses on "entrepreneurship of all kinds", which has catalyzed the development of several centers and institutes providing resources for different types of entrepreneurship. ${ }^{7}$ Babson's entrepreneurial centers and institutes are designed to "provide students with real life experiences to practice what they learn in the classroom, to advance faculty scholarship and business practices, and to share knowledge and experiences across stakeholders." ${ }^{8}$ The activities offered through the entrepreneurial centers and institutes are co-curricular, meaning students do not receive a grade for participating in events, workshops, accelerators, or other activities, but the content is connected to courses and curriculum. ${ }^{9}$ The focus of the centers and institutes is primarily on students and alumni, and 75 percent to 100 percent of activities are designed to support their entrepreneurial endeavors. To this end, Babson offers centers in entrepreneurship, social innovation, family entrepreneurship, women's entrepreneurial leadership, health care entrepreneurship, and a prototyping space (See Appendix 1.1 and Figure 1.2).

All the centers and institutes have an accelerator or incubator of some type. For instance, the Arthur M. Blank Center for Entrepreneurship offers the John E. and Alice L. Butler Launchpad that provides an ecosystem where more than 300 students live and breathe entrepreneurship. The Launchpad provides faculty advising and entrepreneurs in residence, expert office hours, workshops and signature events and programming, co-working space, and access to funding for students. On the other hand, the Center for Women's Entrepreneurial Leadership (CWEL) offers a four-year scholarship program focused on developing entrepreneurial leadership competencies through workshops and working with role models and coaches. CWEL scholars learn to mentor their peers, be role models, and lead within the campus community.

In addition to entrepreneurial focused curricular and co-curricular programming, Babson College was a founder of three multi-country research initiatives. The Global Entrepreneurship Monitor (GEM) was founded in 1999 by Babson College and London Business School. ${ }^{10}$ GEM is a consortium of national teams, primarily associated with top academic institutions, which conducts annual survey-based research on entrepreneurship around the world. GEM is the only global research source that collects data on entrepreneurship directly from individ-

See https://www.babson.edu/about/at-a-glance/entrepreneurship-of-all-kinds/.

See Babson College, Policy on Centers \& Institutes, 2018.

9 Extra-curricular activities are differentiated from co-curricular activities in that they are usually not connected to the curriculum. For example,
sororities and fraternities, and student governance.

${ }_{10}$ See https://www.babson.edu/academics/centers-and-institutes/the-arthur-m-blank-center-for -entrepreneurship/thought-leadership/global-entrepreneurship-monitor/. 


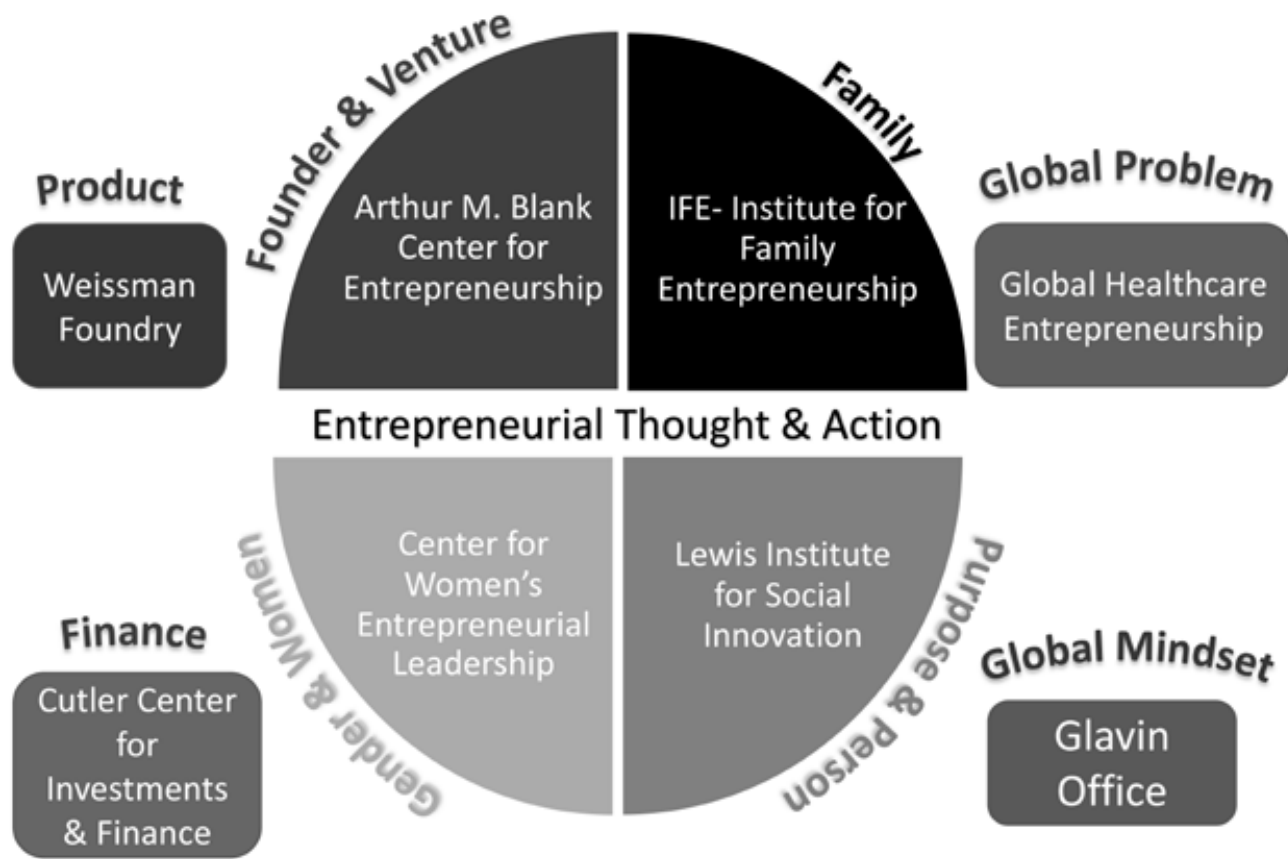

Figure 1.2 Centers and institutes at Babson College

ual entrepreneurs. GEM's Adult Population Survey provides analysis of the characteristics, motivations and aspirations of individuals starting businesses, as well as their attitudes toward entrepreneurship. The National Expert Survey (NES) interviews a select group of experts who offer perspective on the context within which individuals start businesses. These unique GEM surveys benefit stakeholder groups including educators, policy-makers and entrepreneurs. As a founder and lead sponsor of the GEM project, Babson College has led authorship on a number of global and special reports. The foundational research of GEM connects to the classroom as a basis for entrepreneurship courses on campus and abroad. For example, international entrepreneurship courses and offshore courses draw from GEM data to help students better understand the entrepreneurial context in different countries.

Babson was also a founder of the Successful Transgenerational Entrepreneurship Practices (STEP) family business research project in 2005, along with six international affiliates. ${ }^{11}$ The STEP Project is a global applied research initiative that explores the entrepreneurial process within business families. It generates solutions that have immediate application for family leaders. The project includes qualitative research with more than 100 case studies of families around the world, and a quantitative survey that explores the entrepreneurial orientation of families and their businesses. STEP Project findings have directly influenced the creation of family entrepreneurship courses, in particular a peer forum where students meet in teams with a facilitator to work together on challenges each student has in their family business.

11 See https://www.babson.edu/about/news-events/babson-announcements/step-book-series/. 
The Diana Project was launched in 1999 by five professors as a virtual organization, but in 2005 became permanently hosted at Babson College. The Diana Project conducts research activities, forums, and scholarship focused on gender and women's entrepreneurship (Brush et al., 2020). This research was the first to explore growth-oriented women entrepreneurs' access to venture capital, and to provide facts and statistics outlining the extent of the gender gap. The founders received the premier Global International Research Award; ${ }^{12}$ and the research has evolved into the Diana International Research Institute (DIRI), dedicated to being the source of all research, as well as policy, practitioner and educator information, about women's entrepreneurship. ${ }^{13}$ The Institute brings together a global community of stakeholders to conduct, translate and disseminate rigorous research about women entrepreneurs that can impact teaching, policy and practice. Notably, research from the Diana Project influenced curriculum and courses, and it resulted in the creation of a women's accelerator, the WIN Lab, within the Center for Women's Entrepreneurial Leadership. ${ }^{14}$

Babson's outreach to the local community began with the creation of the Academy of Distinguished Entrepreneurs (ADE) award and ceremony in $1977 .{ }^{15}$ This award ceremony recognizes world-class entrepreneurs who have contributed to the development of free enterprise throughout the world, as well as significant social and economic value. Inductees include well-known entrepreneurs such as Steve Forbes, founder of Forbes Magazine, Magic Johnson, CEO of Magic Johnson Companies, Michael Bloomberg, founder of Bloomberg L.P., Kay Koplovitz, founder of USA Networks, Tom Stemberg, founder of Staples, and Henri Termeer, founder of Genzyme. Recognizing these entrepreneurs has engaged them with Babson College and Babson students. Babson College also conducts outreach for entrepreneurial activities. Some examples include: acting as the host and curriculum developer of the Goldman Sachs 10,000 Small Business Training Program; holding bootcamps and training programs for entrepreneurs, such as the James Beard Foundation, the Women's Entrepreneurial Leadership Program for women chefs and owners, and also the Santander Bank-sponsored Cultivate Small Business Program for start-up food entrepreneurs.

In sum, Babson has a continuing commitment to providing resources and support for entrepreneurial activities in the curricular, co-curricular, research and outreach areas. However, we find that in our experience, innovations and best practices emerge from the intersections across these four domains. The next section highlights innovative activities at these intersections.

\section{INNOVATION IN BABSON'S ENTREPRENEURSHIP EDUCATION ECOSYSTEM}

It is well recognized that most new ideas are combinations of other ideas. Combinations of product features, services and products, distribution channels, and materials can all lead to innovation (Sloane, 2017). At Babson College, we find that the most innovative programs

\footnotetext{
12 See https://www.e-award.org/.

13 See https://www.babson.edu/academics/centers-and-institutes/center-for-womens-entreprene urial-leadership/diana-international-research-institute/.

14 See https://www.babson.edu/academics/centers-and-institutes/center-for-womens-entreprene urial-leadership/cwel-programs/win-lab-accelerator/.

15 See https://www.babson.edu/academics/centers-and-institutes/the-arthur-m-blank-center-for -entrepreneurship/awards/academy-of-distinguished-entrepreneurs/.
} 
and initiatives have emerged from the intersections across the four domains: curricular, co-curricular, research and outreach. We highlight a few unique programs below that reflect how combinations of activities have had greater impact. For each program we consider the purpose, how it arose, who runs it and where it runs, how it is executed, challenges, metrics, what works well, and the intersection of the domains where the program resides.

\section{The Family Entrepreneurship Amplifier Program ${ }^{16}$}

Description and purpose: Informed by family theory research, this program includes curricular and co-curricular activities over three years of the undergraduate experience (sophomore through senior), each year emphasizing a different aspect of family understanding. This application-based program requires that parents of participants engage in the program and the activities.

How it arose: Given that 40 percent of Babson students come from family businesses, and they intend to return to their family business sometime after graduation, we identified a need to provide programming for students in family businesses. Because there was not enough room in their schedule for credit-bearing courses in all four years of the program, the program was designed as a mixed curricular and co-curricular experience.

Who runs it and where it runs: This program is taught by Babson faculty and coordinated by the Institute for Family Entrepreneurship (IFE), which also runs workshops, events and other programming. The program runs on the Babson campus.

How the program is executed: The program is organized into three modules: family understanding (sophomore), business understanding (junior), and launching an entrepreneurial opportunity (senior). Students are supported by a family member during the three years, and this family member agrees to work with the student, who will propose an entrepreneurial opportunity to pursue within their family business at the end of the program.

Metrics: This program is only one year old, but the metrics include parent engagement throughout the program, student retention in the program, and implementation of entrepreneurial initiatives at graduation. Further, this program allows the College's communication and touchpoint to be with a family, not just the student.

Challenges: Significant organization and coordination of resources, and the need to determine what should be curricular (graded) and what should not be graded. When parents cannot participate, there is a need to create additional programming for interested students. Funding.

What works well: A key aspect is conducting interviews with the parents of students at the beginning of the program to engage families early in the process.

Domain intersection: The Amplifier sits at the intersection of curricular and co-curricular, with a portion of the activities being outreach, because of parents' engagement in the program.

16 See https://www.babson.edu/academics/centers-and-institutes/institute-for-family-entreprene urship/programs-and-events/family-entrepreneurship-amplifier-course/. 


\section{The Women Innovating Now (WIN) $\mathbf{L a b}^{17}$}

Description and purpose: The Babson WIN Lab provides a program for women entrepreneurs to grow and scale their businesses through engagement with an inspiring community, rigorous milestone planning, network development, and coaching.

How it arose: The WIN Lab was inspired by a finding of the Diana Project research that growth-oriented women entrepreneurs were very unlikely to receive venture capital, ${ }^{18}$ and also by the fact that no women entrepreneurs were finalists in Babson student business plan competitions. As a result, the decision was made to create an accelerator for women entrepreneurs. The funding was supplied by grants and corporate sponsors.

Who runs it and how it runs: This program is taught by faculty and expert practitioners from the Center for Women's Entrepreneurial Leadership. It is run at the Babson Campus in Boston and at a location in Miami. In Miami, participants are local community members, and in Boston, it is a combination of local women entrepreneurs and students. Students have the option to take the WIN Lab for credit or non-credit.

How the program is executed: This is a five-month business curriculum focused on growing and scaling businesses. It includes one-on-one coaching and access to experts in a variety of industries. Every participant creates an action plan with milestones that they need to accomplish during the program. The program concludes with a pitch competition.

Metrics: Since the launch of the WIN Lab, more than 184 founders have participated and raised more than $\$ 16$ million. Among company participants, 75 percent are still in business. The program has won several awards and is listed as a main contributor to Babson College's ranking by College Magazine as the No. 1 school for women entrepreneurs in the world.

Challenges: Because this is an out-of-classroom experience, there can be a conflict with student class schedules. In addition, funding is a challenge.

What works well: An important part of the program is engaging different levels of mentors, those who can dedicate consistent time to work one-on-one with participants. Mentors who are "masterminds" and role models participate on an infrequent basis.

Domain intersection: This program sits at the intersection of co-curricular and research because it was inspired by research. Also, research conducted by the Center for Women's Entrepreneurial Leadership and the Diana International Research Institute continue to inform the program. For instance, a recent report sponsored by the Diana International Research Institute that explored models for financing women entrepreneurs has influenced programming for the WIN Lab. This program began as a purely co-curricular experience, but now students have the option to take it for course credit.

\footnotetext{
See http://www.thewinlab.org/.

See https:/www.babson.edu/academics/centers-and-institutes/center-for-womens-entreprene

18 See https://www.babson.edu/academics/centers-and-institutes/center-
urial-leadership/diana-international-research-institute/research/diana-project/.
} 


\section{FutureLab on Mobility: Lewis Institute of Social Innovation ${ }^{19}$}

Description and purpose: Started in spring 2019, the FutureLab on Mobility seeks to create equity, as well as economic, social and environmental progress in partner communities, by exploring and developing ideas for and solutions to mobility-related dilemmas. The FutureLab on Mobility is a collaboration between Babson College and the Toyota Mobility Foundation. Their shared belief is that mobility is at the heart of many important societal issues, including individual and community health, economic opportunity, education, equity, access, inclusion, and every United Nations Sustainable Development Goal (SDG).

How it arose: The program arose because a donor was interested in mobility. This person determined that in order to study forms of mobility, local community members needed to convene and work together in partnership. Members of the Toyota family were alumni of Babson College.

Who runs it and how it runs: The program runs both on campus in Wellesley and downtown in the city of Boston. It involves participation from the MBTA, the Massachusetts Office of Elder Affairs, Newton-Wellesley Hospital, and elder patients. The course is taught by a Babson faculty member and practitioner expert.

How the program is executed: The program follows the Toyota Foundation approach, which is to identify, clarify and break down problems, analyze root causes, and test countermeasures. It is organized around three premises: bringing together diverse stakeholders, co-creating solutions with communities, and multi-sector experimentation and collaboration. Students participate in an intensive, project-based, discovery and action learning experience that involves dialogue with stakeholders, assessing current systems and infrastructure, as well as testing and retesting ideas and solutions. The program is a multi-level analysis investigating how elder mobility in the health care sector will impact individuals, communities, the economy and the environment. On the co-curricular side there are lectures and workshops on campus, as well as required participation in local events and activities related to elder-care mobility.

Metrics: This program is currently in the first full year. The metrics are based on the extent to which new solutions are adopted by stakeholders, and on community engagement and participation. This corporate-sponsored program is unique in scope and level of engagement. The FutureLab model can be applied to other sustainable development goals.

Challenges: This program requires students to work in the local community. As a result, it also requires transportation and scheduling, which accommodates student course structure.

What works well: Students enjoy working on a real-world problem that has important implications for many stakeholders. The multi-pedagogy approach allows students to participate in the structure and flow of the course.

Domain intersection: This program operates at the intersection of curricular and outreach. This is a class that requires student engagement in the community to work on a relevant social problem. In addition, data is being collected and a research report will be an outcome of this effort to reflect the model, approach and impact.

19 See https://www.babson.edu/academics/centers-and-institutes/the-lewis-institute/action-tanks/ futurelab-on-mobility/. 


\section{Babson Entrepreneurial Leadership Academies Tanzania Course ${ }^{20}$}

Description and purpose: The Babson Entrepreneurial Leadership Academies (BELA) course brings teams of volunteers, including students, staff, faculty, alumni, and friends, to various countries around the world to teach entrepreneurship to high school students. The BELA Tanzania program is designed for students to gain entrepreneurial leadership skills, develop self-awareness, learn teaching and communication skills, and perform an important service activity.

How it arose: The program emerged from a management consulting field experience in which undergraduates traveled to Tanzania and worked with a family on site, together teaching entrepreneurship to high school students.

Who runs it and how it runs: It is run through the Office of Faith and Service and the Glavin Office of International Education. The program is run by volunteer faculty and staff who organize the pre-trip training course on teaching entrepreneurship, and sessions on the culture and history of Tanzania, which take place two months prior to the 14-day trip.

How the program is executed: This is an application-based service program in which students volunteer to participate, although they take a 14-hour non-credit seminar on teaching entrepreneurs. Students pay their own expenses, and this is an ungraded activity. Students teach Monday through Friday, running the academy for approximately 100 students representing five high schools from the Karatu region of Tanzania.

Metrics: Since 2014, more than 110 Babson students have traveled to Tanzania, and more than 700 Tanzanian high school students have participated in entrepreneurship training. Babson has received significant publicity in Tanzania and the program is highly acclaimed. The program was expanded to Guatemala, where 60 high school students participated.

Challenges: The cost of the program, approximately $\$ 2700$, is a challenge.

What works well: Students create innovative teaching exercises to share with students who follow them the next year in the program, and these are archived and shared.

Domain intersection: This program is at the intersection of co-curricular and outreach, as students volunteer to participate in this service-learning program. They are providing entrepreneurship education for under-served youth in Tanzania.

\section{CONCLUSIONS AND IMPLICATIONS}

This chapter has explored how the intersections across domains of the entrepreneurship education ecosystem - curricular, co-curricular, research and outreach - can be a source of innovation that enriches student experience, creates unique brand identification for the College, and impacts the community. For colleges and universities seeking to innovate within their entrepreneurship education ecosystems, below are a few steps to take, moving forward.

1. Evaluate it: Assess your entrepreneurship education ecosystem using the domain and dimensions framework, to determine strengths and weaknesses. What are true assets that distinguish your school? Where are competitors better? Then, where are there intersections? Create an idea, think big, but make sure it differentiates your school. 
2 Do it: Take action using an entrepreneurial approach. This requires experimentation. Try things on a small scale, see what the results are, modify and repeat.

3. Live it: Once you have identified an innovation, evolve it to a larger scale, and communicate it to a wider audience. Bring new stakeholders aboard to participate.

4. Embrace it: Develop metrics for determining the value and impact of the innovation, and metrics for improvement. Ensure the plan is connected to the larger strategy of your school, and that it is continually improved.

In following these action steps, there are also key processes that can enhance success. These are collaboration, communication, and an entrepreneurial approach.

Collaboration: For innovations to work, it is important for faculty and staff, and sometimes members of the community, to collaborate, meaning design and execute together. In the Babson examples noted above, the programs were co-created with a primary goal of enhancing the student learning experience. This required a flexible perspective (what is a faculty role and what is a staff role) and being guided by an innovative outcome.

Communication: A key element was intense communication about the programs, both inside and outside the College. During the emergence of these programs and to start generating enthusiasm and buy-in, they were socialized with various groups and stakeholders, students, faculty department chairs, program managers, alumni, and College leadership. In addition, social media and marketing outreach specific to these programs were set up, such as bi-weekly newsletters, Facebook groups, website presence, and direct emails to students and community. This communication increased engagement and participation, generating further innovations and ideas to include in these programs. In the case of the WIN Lab, students entered several competitions for innovation in university programs, which boosted visibility and brought in new sources of funding.

Entrepreneurial Approach: As an entrepreneurial college, we applied our Entrepreneurial Thought and Action (ET\&A) methodology to these innovations. ${ }^{21}$ As previously stated, ET\&A is based on four premises: start with the means at hand, pay only what you can afford to lose, take small action, enroll others and build on what you learn. Instead of spending a lot of time planning and looking for significant resources, all these programs emerged with a collaborative team of staff, faculty and stakeholders coming together around an idea, followed by action - small steps to test the idea, reflect, and build on results. In three cases, except for FutureLab, few or no financial resources and no personnel were available at the start. The programs began with action, small steps which gathered momentum.

In conclusion, for colleges and universities to be distinct, to provide unique learning experiences for their students and to continue to amplify their positioning in the marketplace, it is essential to innovate. Innovation occurs at the intersection of the domains - research, curricular, co-curricular, and outreach - and it can be effectively implemented using collaboration, communication, and an entrepreneurial approach.

\footnotetext{
${ }_{21}$ See https://www.babson.edu/about/at-a-glance/entrepreneurial-thought--action/.
} 


\section{REFERENCES}

Bosma, N. and Kelley, D. 2019. The Global Entrepreneurship Monitor 2018/2019 Global Report. Wellesley, MA: Babson College.

Brush, C. 2014. Exploring the concept of an entrepreneurship education ecosystem. In S. Hoskinson and D. Kuratko (eds), Innovative Pathways for University Entrepreneurship in the 21st Century: Innovation and Economic Growth, Vol. 24. Bingley: Emerald Publishing, pp. 25-40.

Brush, C., Greene, P. and Welter, F. 2020. The Diana Project: A legacy for research on gender in entrepreneurship. International Journal of Gender and Entrepreneurship, 12(1), 7-25.

Busenitz, L.W., West, G.P. III., Shepherd, D., Nelson, T., Chandler, G.N. and Zacharakis, A. 2003. Entrepreneurship research in emergence: Past trends and future directions. Journal of Management, 29(3), 285-308.

Davidsson, P. 2016. The field of entrepreneurship research: Some significant developments. In D. Bogenhold, J. Bonnet, M. Dejardin and D. Garcial Perez de Lema (eds), Contemporary Entrepreneurship: Multidisciplinary Perspectives on Innovation and Growth. Cham: Springer Publishing, pp. 17-30.

Feld, B. 2012. Startup Communities: Building an Entrepreneurial Ecosystem in your City: Hoboken, NJ: John Wiley \& Sons.

Fetters, M., Greene, P., Rice, M. and Butler, J. 2010. The Development of University-Based Entrepreneurship Ecosystems: Global Practices. Cheltenham, UK and Northampton, MA, USA: Edward Elgar Publishing.

Finkle, T.A., Menzies, T.V., Kuratko, D.F. and Goldsby, M.G. 2013. An examination of the financial challenges of entrepreneurship centers throughout the world. Journal of Small Business and Entrepreneurship, 26(1), 67-85.

Greenberg, D. and Hunt, J. 2015. Developing entrepreneurial leaders - integrating entrepreneurship education and organizational behavior in the first year. In V. Crittenden, K. Esper, N. Karst and R. Slegers (eds), Evolving Entrepreneurial Education: Innovation in the Babson Classroom. Bingley: Emerald Publishing, pp. 99-118.

Isenberg, D. 2010. How to start an entrepreneurial revolution. Harvard Business Review, 88(6), 40-50.

Sarasvathy, S. 2008. Effectuation. Cheltenham, UK and Northampton, MA, USA: Edward Elgar Publishing.

Sloane, P. 2017. A Leader's Guide to Lateral Thinking Skills: Unlock the Creativity in you and your Team. London: Kogan Page Ltd.

Spigel, B. 2017. The relational organization of entrepreneurial ecosystems. Entrepreneurship Theory and Practice, 41(1), 49-72.

World Economic Forum. 2013. Entrepreneurial Ecosystems around the Globe and Company Growth Dynamics. Davos: World Economic Forum. 


\section{APPENDIX 1.1}

\section{BABSON'S ENTREPRENEURIAL CENTERS AND INSTITUTES}

\section{The Arthur M. Blank Center}

Dedicated in 1998, The Arthur M. Blank Center for Entrepreneurship is the nerve center for entrepreneurial activity at Babson. The 6000-square-foot center was named in honor of Arthur M. Blank '63, H'98 (co-founder of The Home Depot). The Center accelerates the practice of entrepreneurship by providing Babson's emerging entrepreneurs with access to events, workshops, mentoring, and competitions that enable them to test and refine their founder skills. The Butler Launchpad is the hub of this entrepreneurial ecosystem, connecting our students and alumni with the broader business and entrepreneurial community through a series of programs and learning experiences that support our entrepreneurs along their journey. Included in these programs are two of Babson's Signature Events: Rocket Pitch and B.E.T.A. Challenge, as well as the highly regarded Summer Venture Program that accelerates the top 15 student ventures at Babson each year. The Blank Center also houses the Global Entrepreneurship Monitor (GEM) global research project, and hosts the Babson College Entrepreneurship Research Conference (BCERC).

http://www.babson.edu/blankcenter.

\section{The Center for Women's Entrepreneurial Leadership}

Babson was the first business school to establish a center focused on women entrepreneurial leaders when it launched the Center for Women's Entrepreneurial Leadership (CWEL) in 2000. Since its inception, CWEL has made progress in its mission of creating an entrepreneurial world in which all people thrive by dramatically increasing the impact of female leaders in every sector, enlightening the global community about the value of women's entrepreneurial leadership, and empowering women and men to transform themselves, nations and generations while advancing equity, prosperity and progress for all. The Center does this by empowering women leaders through educational programs, events and research, which impact a diverse set of stakeholders from around the world. CWEL is the home of the CWEL Scholars program, which helps undergraduate women to develop leadership skills, and the award-winning Women Innovating Now (WIN Lab) venture accelerator for women entrepreneurs, which operates in Boston and Miami.

http://www.babson.edu/cwel.

\section{The Diana International Research Institute}

The Diana International Research Institute (DIRI) is the premier global research institute dedicated to being the source of all research, policy, practitioner and educator information for women's entrepreneurship. By supporting and connecting a worldwide community of stakeholders, we bring together the brightest minds conducting, translating and disseminating rigorous research and data about women's entrepreneurship that can directly impact teaching, 
policy and practice. The Institute sponsors an annual global research conference on topics of gender and women's entrepreneurship; offers quarterly educator roundtables on teaching; and maintains a global network of scholars.

http://www.babson.edu/diana-international-research-institute.

\section{The Institute for Family Entrepreneurship}

The Institute for Family Entrepreneurship (IFE), launched in 2018, is a hub for research, resources and innovative programming dedicated to entrepreneurial students and their families. The business, investment, and philanthropic activities of entrepreneurial families are significant drivers of the global economy. Consistent with Babson's leadership in entrepreneurship education, and unlike any other school, Babson's commitment to family entrepreneurs recognizes that families, not just family businesses, drive entrepreneurial behavior. This includes the support of multigenerational family businesses, family foundations, startups and acquisitions supported by families, spousal startups, entrepreneurial family members embarking on separate ventures, and many other value-creating family activities. Core activities include The Entrepreneurial Family Network, the Generational Entrepreneurship Amplifier, and The Successful Transgenerational Entrepreneurship Project (STEP) research project. http://www.babson.edu/ife.

\section{The Kerry Murphy Healey Center for Global Healthcare Entrepreneurship}

The Kerry Murphy Healey Center for Global Healthcare Entrepreneurship (GHE Center) was named in September 2019 as an expansion of the former Schlesinger Fund for Global Healthcare Entrepreneurship and has been housed within the Lewis Institute for Social Innovation at Babson since 2013. The Center is supported by the Kletjian Foundation whose mission is to build collaborative networks and support entrepreneurial leaders that promote health equity everywhere. Key activities include research, events and courses that activate entrepreneurial leaders to recognize, implement and grow opportunities to promote health for all.

\section{The Lewis Institute}

Founded in July 2010 with a generous grant from Alan and Harriet Lewis of Grand Circle Corporation, The Lewis Institute serves as an integrated, objective and accessible resource to the Babson community. Through its work, the Institute nurtures fruitful collaborations among diverse parties with a shared commitment to making a difference. The Lewis Institute illuminates pathways for students, faculty, staff, foundations and corporate partners seeking social innovation solutions. By drawing upon Babson's core methodology of Entrepreneurial Thought and Action ${ }^{\circledR}$, the Institute activates unexpected and fruitful collaborations and integrative designs for action. Notable programs are the Youth Impact Lab, courses and programming for high school students, Babson Board Fellows, a program preparing students to serve on non-profit boards, and Community Table, a weekly open forum to discuss and generate ideas.

http://www.babson.edu/lewis. 


\section{The Stephen D. Cutler Center for Investments and Finance}

The Cutler Center was founded in 2000 with a generous gift from Stephen D. Cutler MBA'61 and his wife, Alice. The Cutler Center advances financial education and improves the skill set and marketability of Babson students. The Center is dedicated to advancing finance education and improving the marketability of Babson students by providing programs and cutting-edge resources that enrich the student learning experience, support faculty research, and engage our alumni community. The Cutler Center furthers Babson's innovative and practical approach to finance education and enables industry practitioners, faculty and students to collaborate and learn from one another. Key initiatives include the Babson College Fund, where students manage a part of the College's endowment, weekly webinars on finance and several courses which take place in the state-of-the-art finance lab.

http://www.babson.edu/cutler.

\section{The Weissman Foundry}

The Weissman Foundry was established in 2018 and is centrally located between the hearts of Babson's and Olin's campuses on Map Hill Drive across from Trim Parking Lot. The approximately 9800-square-foot building will have space available for student project workspaces, prototyping resources, experiential teaching spaces, social kitchen, and conference and group study space. The purpose of the building is to serve the needs of students pursuing entrepreneurial ventures where physical prototyping is central, promoting greater collaboration with the Olin College of Engineering, and Wellesley College; and complementing existing "innovation spaces" on campus available in the Olin Graduate School of Business and the Leonard A. Schlesinger First Year Innovation Center, particularly by providing a dedicated "messy" project workspace where students can work on projects at all hours. The Weissman Foundry is an open-door design studio, inspiring transdisciplinary innovative collaboration between Babson, Olin and Wellesley for the advancement of new or existing projects. Signature events include the Untitled Fashion show, Foundry Fellowships and the Scouts Program, where students are leaders and mentors in the Foundry.

http://www.foundry.babson.edu/. 